\title{
SENTENCIA DEL TRIBUNAL CONSTITUCIONAL DE 8 DE JUNIO DE 2017
}

\author{
Olga Carreras Manero \\ Área de Derecho Financerio y Tributario. \\ Departamento de Derecho de la Empresa \\ Facultad de Derecho. Universidad de Zaragoza \\ olgacarr@unizar.es \\ Sabina De Miguel Arias \\ Área de Derecho Financiero y Tributario. \\ Departamento de Derecho de la Empresa \\ Facultad de Derecho. Universidad de Zaragoza \\ sabinade@unizar.es
}

\section{ANTECEDENTES: RECURSO DE INCONSTITUCIONALIDAD Y ALEGACIONES DE LA ABOGACÍA DEL ESTADO}

La Sentencia del Tribunal Constitucional de 8 de junio de 2017 ha venido a declarar la inconstitucionalidad de la declaración tributaria especial —la llamada «amnistía fiscal»— aprobada en 2012.

Así, el 25 de junio de 2012 se promovió recurso de inconstitucionalidad contra la disposición adicional primera del Real Decreto-ley 12/2012, de 30 de marzo, por el que se introducían diversas medidas tributarias y administrativas dirigidas a la reducción del déficit público ${ }^{1}$, alegándose, a estos efectos, una posible vulneración de los arts. 86.1 y 31.1 CE.

En este sentido, aquellos diputados que interpusieron el referido recurso consideraron que el hecho de que los contribuyentes por el Impuesto sobre la Renta de las Personas Físicas (IRPF), el Impuesto sobre Sociedades (IS) y el Impuesto sobre la Renta de no Residentes (IRNR) pudieran tributar por una prestación única del 10 por 100 del valor de los bienes y derechos declarados, con exclusión de los oportunos intereses de demora, recargos y sanciones, venía a suponer una clara vulneración de los preceptos arriba mencionados.

1 La misma fue objeto de modificación posterior por el Real Decreto-ley 19/2012, que dio lugar a la aprobación de la Ley 12/2012, de 26 de diciembre, tras su tramitación como proyecto de ley. 
En efecto, es preciso recordar que el Real Decreto-ley 12/2012 permitía que, cuando se reconociera la titularidad de derechos procedentes de rentas no declaradas en los períodos impositivos previos a la entrada en vigor de la citada norma —esto es, el 30 de noviembre del 2012_, se realizase un pago del 10 por 100 del importe de las rentas declaradas en sustitución de todas las obligaciones tributarias exigibles, incluso de la concreta cuota tributaria resultante de tal declaración ${ }^{2}$.

A este respecto, en dicha disposición adicional, bajo el título de «Declaración tributaria especial», se habilitaba a los contribuyentes del IRPF, del IS y del IRNR «que sean titulares de bienes o derechos que no se correspondan con las rentas declaradas en dichos impuestos» a presentar una declaración «con el objeto de regularizar su situación tributaria, siempre que hubieran sido titulares de tales bienes o derechos con anterioridad a la finalización del último período impositivo cuyo plazo de declaración hubiera finalizado antes de la entrada en vigor de esta disposición». A dicha declaración se acompañaba el ingreso de «la cuantía resultante de aplicar al importe o valor de adquisición de los bienes o derechos (...) el porcentaje del 10 por 100», sin que fueran exigibles sanciones, intereses ni recargos y teniendo el importe declarado por el contribuyente la consideración de renta declarada. El plazo para la presentación de las declaraciones y su ingreso finalizaba el 30 de noviembre de 2012, no siendo posible, empero, acogerse a lo previsto en esta disposición «en relación con los impuestos y períodos impositivos respecto de los cuales la declaración e ingreso se hubiera producido después de que se hubiera notificado por la Administración tributaria la iniciación de procedimientos de comprobación o investigación tendentes a la determinación de las deudas tributarias correspondiente a los mismos».

De acuerdo con ello, la declaración tributaria especial posibilitaba aflorar aquellos capitales que permanecían ocultos, regularizándose, de este modo, la situación tributaria del contribuyente a cambio del pago del referido 10 por 100. Es más, dicha regularización exoneraba, incluso, de responsabilidad penal, aunque la infracción en su día cometida hubiera sido constitutiva de delito contra la Hacienda Pública ${ }^{3}$.

2 Ahora bien, en la práctica el tipo impositivo real no fue del 10 por 100, sino del 3 por 100 , en la medida en que la base de la regularización se limitó a bienes no declarados adquiridos en ejercicios no prescritos.

3 F. PÉrez Royo, «Más que una amnistía», Revista Española de Derecho Financiero, núm. 154 (2012), pp. 9 y ss. 
Siendo esto así, los recurrentes originarios de la sentencia objeto de examen consideraban que con esta regularización fiscal no sólo se vulneraba directamente la capacidad económica contenida en el art. 31.1 CE, sino que, a su vez, venía a establecerse ex novo un nuevo gravamen de los referidos impuestos mediante decreto-ley, materia que, a juicio de aquéllos, se encuentra sometida al principio de reserva de ley stricto sensu, estando vedada, por consiguiente, al decreto-ley.

De ahí que se entendiera que al no poderse crear o implantar un nuevo tributo ni determinar sus elementos esenciales por este tipo de norma, se vulneraba, además, el art. 86.1 CE, en la medida en que se alteró, de modo evidente, la posición del obligado a contribuir de acuerdo con su capacidad económica, al modificarse un elemento esencial del tributo que incide, directamente, en la determinación de la carga tributaria.

Junto a ello se ha alegado que esta medida vulneraba otros principios de justicia tributaria recogidos en el art. 31.1 CE; en concreto, el de generalidad - ya que los que se acogieran a la declaración especial quedaban exonerados del deber de contribuir-, de igualdad — en la medida en que los ciudadanos en situaciones jurídicamente comparables son objeto de un trato diferente-, de capacidad económica — por eximir de tributación a los contribuyentes de mayor capacidad económica- y de progresividad —al aplicarse un pago único del 10 por 100 con independencia de la cuantía de la renta declarada- ${ }^{4}$.

En conclusión, ha venido a destacarse el hecho de que el legislador estableció un régimen fiscal mucho más beneficioso para el incumplidor de las normas tributarias que para el resto de los contribuyentes, sin que existiese una justificación objetiva y razonable que legitimase ese trato dispar.

No obstante lo anterior, el abogado del Estado, en su escrito de alegaciones, puso de manifiesto que la referida regularización de las rentas ocultas se justificaba en la gravedad de la crisis económica y, además, a su juicio, ni se creaba un nuevo tributo ni se reformaba ningún tributo existente, sino que, simplemente, se introdujo un procedimiento especial de regularización de rentas no declaradas, delimitando el ámbito subjetivo, objetivo y

4 A este respecto, para los diputados recurrentes la regularización prevista no sólo exoneraba de la imposición de sanciones, sino también de la tributación por las obligaciones pendientes, al sustituir esta obligación por un pago del 10 por 100 que no llegaba siquiera a cubrir la cantidad que correspondería abonar en concepto de recargos o intereses. Así, han puesto de manifiesto que resulta difícil encontrar un argumento jurídico con anclaje constitucional que permita justificar el reconocimiento de beneficios fiscales a los defraudadores. 
temporal del mismo, en aras a cumplir con el principio de estabilidad presupuestaria del art. 135 CE.

Asimismo, la Abogacía del Estado consideró que el legislador puede decidir, en un momento determinado y con una vigencia temporal, introducir junto con el procedimiento ordinario de regularización otro excepcional sin que se vulnere el principio de igualdad; es más, y a su modo de ver, si el coste de la regularización fuese alto, pocos defraudadores se acogerían al mismo, razón por la cual sólo con un coste bajo se consigue el objetivo perseguido, lo que supone que deba admitirse un cierto sacrificio de los principios tributarios del art. 31.1 CE, singularmente el de igualdad, en atención a otros principios constitucionalmente relevantes, como es el de estabilidad presupuestaria.

\section{ARGUMENTACIÓN JURÍDICA DE LA DECLARACIÓN DE INCONSTITUCIONALIDAD}

Siendo esto así, el Tribunal Constitucional, en la sentencia ahora examinada, recuerda su doctrina acerca del principio de reserva de ley y los límites para establecer o modificar tributos mediante decreto-ley.

A estos efectos, se entiende que el establecimiento de prestaciones patrimoniales de carácter público debe hacerse con arreglo a la ley a fin de «garantizar que las prestaciones que los particulares satisfacen a los entes públicos sean previamente consentidas por sus representantes», configurándose de este modo como «una garantía de autoimposición de la comunidad sobre sí misma y, en última instancia, como una garantía de la libertad patrimonial y personal del ciudadano» ${ }^{5}$.

De acuerdo con ello, puede afirmarse que cuando el art. 86.1 CE excluye del ámbito del decreto-ley a los deberes consagrados en el título I de la Constitución, únicamente está impidiendo aquellas intervenciones o innovaciones normativas que afecten no de cualquier manera, sino de forma relevante o sustancial, al deber constitucional de «todos» de contribuir al sostenimiento de los gastos públicos (art. 31.1 CE).

Ahora bien, se ha puesto de manifiesto que no existe óbice alguno, desde el punto de vista constitucional, para que a través de un decreto-

5 Vid. a este respecto las Sentencias del Tribunal Constitucional 185/1995, de 14 de diciembre; 233/1999, de 16 de diciembre; 3/2003, de 16 de enero, y 136/2011, de 13 de septiembre. 
ley se puedan establecer, modificar o derogar prestaciones patrimoniales de carácter público, siempre que concurra una situación de extraordinaria urgencia que justifique el uso de este instrumento normativo y que, a través de él, no se afecte al deber de contribuir al sostenimiento de los gastos públicos del art. $31.1 \mathrm{CE}^{6}$.

Así, en palabras del Tribunal Constitucional, el hecho de que el establecimiento de prestaciones patrimoniales de carácter público esté sujeto al principio de reserva de ley (art. 31.3 CE) «no se deriva necesariamente que la citada materia se encuentre excluida del ámbito de regulación del decreto-ley, que podrá penetrar en la misma siempre que se den los requisitos constitucionales del presupuesto habilitante y no «afecte» en el sentido constitucional del término, a las materias excluidas» ${ }^{7}$.

Siendo eso así, es preciso tener en cuenta que para interpretar de modo correcto el límite material del art. 86.1 CE debe atenderse «al examen de si ha existido "afectación" por el decreto-ley de un derecho, deber o libertad regulado en el título I de la Constitución»; lo que exigirá «tener en cuenta la configuración constitucional del derecho o deber afectado en cada caso y la naturaleza y alcance de la concreta regulación de que se trate» ${ }^{8}$.

En este sentido se ha entendido, de forma reiterada, que el decreto-ley «no podrá alterar ni el régimen general ni aquellos elementos esenciales de los tributos que inciden en la determinación de la carga tributaria, afectando así al deber general de los ciudadanos de contribuir al sostenimiento de los gastos públicos de acuerdo con su riqueza mediante un sistema tributario justo»; en consecuencia, va a vulnerarse el art. 86.1 CE cuando exista una «intervención o innovación normativa que, por su entidad cualitativa o cuantitativa, altere sensiblemente la posición del obligado a contribuir según su capacidad económica en el conjunto del sistema tributario»?

De conformidad con lo anterior, la sentencia viene a abordar la aplicación de esta doctrina en relación con la medida establecida en el Real Decreto-ley 12/2012; esto es, se examina si la disposición adicional de dicha norma afecta (o no) al deber de «todos» de contribuir al sostenimiento de los gastos públicos. Para ello, el Alto Tribunal efectúa un triple

6 Sentencias del Tribunal Constitucional 111/1983, de 2 de diciembre; 60/1986, de 20 de mayo; 182/1997, de 18 de octubre; 189/2005, de 7 de julio, y 139/2016, de 21 de julio.

7 Sentencias del Tribunal Constitucional 245/2004, de 16 de diciembre, y 83/2014, de 29 de mayo.

8 Sentencias del Tribunal Constitucional 182/1997, de 28 de octubre; 329/2005, de 15 de diciembre; 100/2012, de 8 de mayo, y 35/2017, de 1 de marzo.

9 Ibid. 
análisis: 1) determinar en qué tributos concretos ha incidido tal instrumento normativo, así como el grado en que interviene el principio de capacidad económica; 2) qué elementos han resultado alterados por este excepcional modo de producción normativa; 3 ) cuál es la naturaleza y alcance de esta regulación.

A estos efectos, y en relación con la primera cuestión, se ha señalado que quienes pueden acogerse a la regularización prevista en la disposición adicional primera del Real Decreto-ley 12/2012 son los contribuyentes del IRPF, del IS y del IRNR «que sean titulares de bienes o derechos que no se correspondan con las rentas declaradas en dichos impuestos»; por tanto, la medida controvertida va destinada a quienes han dejado de cumplir con la obligación de tributar por los impuestos personales y directos que gravan la renta de las personas físicas o jurídicas, residentes o no, en territorio español.

En este sentido, cabe señalar que el IRPF se erige en uno de «los pilares estructurales» o una de «las piezas básicas» del sistema tributario español; así, a través de este impuesto «se realiza la personalización del reparto de la carga fiscal en el sistema tributario según los criterios de capacidad económica, igualdad y progresividad, lo que lo convierte en una figura impositiva primordial para conseguir que nuestro sistema tributario cumpla los principios de justicia tributaria que impone el art. 31.1 CE», junto con «los objetivos de redistribución de la renta (art. 131.1 CE) y de solidaridad (art. 138.1 CE)». De ahí que se haya considerado que cualquier alteración sustancial en la configuración de los elementos esenciales del IRPF podría alterar el modo de reparto de la carga tributaria que debe levantar la generalidad de las personas físicas que manifiesten una capacidad económica susceptible de gravamen ${ }^{10}$.

A su vez, también el IS constituye la otra de las piezas básicas del sistema tributario y, concretamente, de la imposición directa en España, pues se trata de un tributo global sobre la renta de las personas jurídicas, el cual, con su integración con el IRPF, complementa el gravamen de uno los de índices de capacidad económica.

Por fin, y aunque no cabe deducir lo mismo del IRNR, lo cierto es que este tributo constituye un apéndice inseparable del IRPF y del IS. De este modo, su conjunción sirve para culminar la personalización del reparto de la carga fiscal y el cumplimiento de los principios de justicia tribu-

10 Sentencias del Tribunal Constitucional de 134/1996, de 22 de julio; 182/1997, de 20 de octubre; 46/2000, de 14 de febrero; 137/2003, de 3 de julio, y 189/2005, de 7 de julio. 
taria y de los objetivos de redistribución de la renta. En consecuencia, si bien su concreta alteración no tiene virtualidad suficiente para afectar el modo de reparto de la carga tributaria de la generalidad de los contribuyentes, no cabe duda de que la alteración conjunta entre los tres impuestos del gravamen que soportan la generalidad de las personas podría incidir en tal cuestión.

Junto a lo anterior, y en segundo término, el Tribunal Constitucional entra a valorar aquellos elementos del tributo que han resultado alterados por la disposición adicional impugnada. Así, y aunque la misma no crea una figura tributaria nueva, limitándose a establecer una forma excepcional de regularización de las deudas tributarias pendientes, devengadas y no declaradas, en el ámbito del IRPF, del IS y del IRNR, sí que dispone una manera especial de cuantificación de las rentas no declaradas, sometiéndolas a un tipo de gravamen específico: el 10 por 100 .

Así, con tales medidas - limitación de la responsabilidad tributaria principal y exclusión de las responsabilidades accesorias- se procede a una condonación parcial de la obligación tributaria principal y a una condonación total de las consecuencias accesorias — recargos, intereses y sanciones-.

En último lugar, cabe destacar, sobre la naturaleza y el alcance de la concreta regulación, que ésta sólo podía llevarse a efecto hasta el 30 de noviembre de 2012 y únicamente en relación con los bienes o derechos de los que se fuera titular «con anterioridad a la finalización del último periodo impositivo cuyo plazo de declaración hubiera finalizado antes de la entrada en vigor de esta disposición». Esto es, con carácter general, la norma afectaba a aquellos bienes de los que se era titular hasta el 31 de diciembre de 2010 (dejando de lado las posibles salvedades en relación con el IS y con el IRNR), pues la misma tuvo su entrada en vigor el día de su publicación en el BOE.

Ahora bien, se excluían de aquella regularización, empero, los impuestos y períodos impositivos que, al momento de presentar la declaración, ya estuvieran siendo objeto de procedimientos de comprobación o investigación notificados al contribuyente.

De este modo, y una vez efectuado el análisis anterior, es posible concluir que la referida regularización se dirigió a la totalidad de los contribuyentes de los impuestos directos. Por ello, el Tribunal Constitucional ha entendido que con esta medida normativa se ha afectado a la esencia misma del deber de contribuir al sostenimiento de los gastos públicos que enuncia el art. 31.1 CE, al haberse alterado el modo de reparto de la carga 
tributaria que debe levantar la generalidad de los contribuyentes, en unos términos que resultan prohibidos por el art. 86.1 CE.

En efecto, consideramos que la referida disposición venía a legitimar conductas insolidarias a través del incumplimiento del deber de tributar de acuerdo con la capacidad económica, puesto que a dichos contribuyentes se les ponía en una situación más favorable que aquellos otros que cumplieron de forma voluntaria y en plazo su obligación de contribuir.

Por lo demás, se da respuesta a las alegaciones de la Abogacía del Estado indicándose que ni la gravedad de la crisis económica, ni las recomendaciones de la OCDE, ni las experiencias de otros países justifican la aprobación de medidas dirigidas al aumento de los ingresos o a la reducción de los gastos públicos, pues ello ha de realizarse dentro de los límites y con respeto a las exigencias que la Constitución impone.

A mayor abundamiento, el hecho de que la medida cuestionada pudiera contar, en un momento dado, con una justificación que la legitimase, sería un requisito necesario, pero en ningún caso suficiente, desde el plano constitucional, cuando se introduce mediante el uso de un instrumento normativo a través del cual no puede afectarse al cumplimiento de un deber de los previstos en el título I de la Constitución, como lo es el de contribuir al sostenimiento de los gastos públicos (art. 31.1 CE).

Por último, y a pesar de lo indicado en la Exposición de Motivos del Real Decreto-ley 12/2012, no se trata de una situación similar a la de la exoneración de responsabilidad penal frente a regularizaciones tributarias voluntarias realizadas antes del inicio de actuaciones de comprobación tributaria o de que se interponga la pertinente denuncia o querella, ya que en este tipo de regularizaciones lo que se excluye son las consecuencias punitivas derivadas del incumplimiento de las obligaciones tributarias $^{11}$, pero no se exonera del cumplimiento de la obligación del pago de la deuda tributaria pendiente al momento de la regularización. Por el contrario, el sistema previsto en la disposición adicional controvertida no se limita a excluir las consecuencias accesorias de la responsabilidad tributaria, sino que evita, a su vez, la propia responsabilidad tributaria pendiente de cumplimiento.

En suma, el Alto Tribunal ha venido a concluir que «la adopción de medidas que, en lugar de servir a la lucha contra el fraude fiscal, se aprovechan del mismo so pretexto de la obtención de unos ingresos que se consideran imprescindibles ante un escenario de grave crisis económica, supone

11 Véase el art. 305.4 CP. 
la abdicación del Estado ante su obligación de hacer efectivo el deber de todos de concurrir al sostenimiento de los gastos públicos (art. 31.1 CE)».

De este modo, se legitima como una opción válida «la conducta de quienes, de forma insolidaria, incumplieron su deber de tributar de acuerdo con su capacidad económica, colocándolos finalmente en una situación más favorable que la de aquellos que cumplieron voluntariamente y en plazo su obligación de contribuir». En consecuencia, «el objetivo de conseguir una recaudación que se considera imprescindible no puede ser, por sí solo, causa suficiente que legitime la quiebra del objetivo de justicia al que debe tender, en todo caso, el sistema tributario, en general, y las concretas medidas que lo integran, en particular».

De acuerdo con todo lo anterior, el Tribunal Constitucional declara, por unanimidad, la disposición impugnada inconstitucional y nula, puesto que la medida en ella contenida ha afectado a la esencia del deber de contribuir al sostenimiento de los gastos públicos, lo cual en modo alguno puede llevarse a cabo a través del instrumento normativo excepcional recogido en el art. 86.1 CE, aspecto este que hace innecesario entrar a conocer de la lesión de los principios de capacidad económica, igualdad y progresividad.

Ahora bien, como ha puesto de relieve Martín Queralt, y a pesar de que el fallo encuentra anclaje en una consideración distinta, cabe destacar que la motivación de la sentencia se encuentra «preñada de declaraciones que claramente subrayan que se han vulnerado los principios materiales de justicia tributaria», dado que «la norma afecta a la esencia misma del deber de contribuir al sostenimiento de los gastos públicos, alterando sustancialmente el modo de reparto de la carga tributaria que debe levantar la generalidad de los contribuyentes según los criterios de capacidad económica, igualdad y progresividad que tutela el art. 31.1 de la Constitución» ${ }^{12}$.

\section{ALGUNAS CONSIDERACIONES SOBRE LA DECLARACIÓN DE INCONSTITUCIONALIDAD Y SUS EFECTOS}

Por fin, y en cuanto a los efectos de la sentencia ahora comentada, se prevé que no resultarán susceptibles de ser revisadas, como consecuencia de dicha nulidad, aquellas situaciones jurídico-tributarias firmes, por exi-

12 J. MARTín Queralt, «La amnistía no sólo es inconstitucional porque se aprobó por el decreto-ley», Legal Cinco Días, junio de 2017. 
gencia del principio constitucional de seguridad jurídica previsto en el art. 9.3 CE. Por tanto, vienen a limitarse los efectos retroactivos de la declaración de inconstitucionalidad en aplicación de la teoría prospectiva ${ }^{13}$.

No obstante lo anterior, y aunque en muchas situaciones el pronunciamiento no va a tener ninguna trascendencia, pues la decisión del Tribunal no afectará a las regularizaciones tributarias firmes que se realizaron al amparo de la norma anulada, existen actuaciones que distan de haber alcanzado firmeza ${ }^{14}$ y que pueden crear situaciones difíciles de solucionar ${ }^{15}$.

13 Cuyo origen tuvo lugar con la Sentencia del Tribunal Constitucional 45/1989, de 29 de febrero. Ahora bien, a juicio de C. CHeCA GONZÁLEZ, La responsabilidad patrimonial de la Administración tributaria, Pamplona, Aranzadi, 2011, p. 161, dicha tesis tiene su razón de ser desde un punto de vista pragmático, pero es difícilmente defendible desde una óptica estrictamente jurídica, pues origina un déficit de control constitucional tributario.

14 Por ejemplo, la sentencia no va a resultar aplicable ni a situaciones prescritas ni a comprobaciones donde se haya dictado liquidación no susceptible de revisión, pero existirán otras sí susceptibles de revisión.

15 J. MARTín Queralt, «La amnistía no sólo es inconstitucional...», op. cit. 